\title{
Change of Awareness and Characteristics of Student Groups in Class Creating PowerPoint Slides to Introduce Books
}

\author{
Isao Miyaji \\ National Institute of Technology, Toyama College \\ Musa 1392, Kita-ku, Okayama 701-2141 Japan \\ Tel: 81-86-229-3799Ｅ-mail: s8u3m3i2re@hotmail.co.jp
}

Received: June 6, 2017 Accepted: July 21, 2017 Published: August 1, 2017

doi:10.5296/jse.v7i3.11354 URL: https://doi.org/10.5296/jse.v7i3.11354

\begin{abstract}
This paper deals with the class where university students recommended books they are interested in by means of PowerPoint slides. In this course, they were required to create PowerPoint slides to introduce books by inserting animations and narrations. It applied active learning in combination with evaluation and revision activities to enhance their computer skills, to raise awareness towards various types of skills necessary for problem solving and to nurture active thinking. It particularly aims not only to acquire PowerPoint skills but also to develop their skills in expression, project planning and suggestion. This paper informs of the content of the course, proves change of awareness, and reports characteristics of student groups by classifying students according to principal components in rating scale values of awareness.
\end{abstract}

Keywords: Book recommendation, creating PowerPoint slides, evaluation, revision, problem solving skills 


\section{Introduction}

There are a number of attempts to propose new ways of teaching and to practice effective classrooms. Currently, the Central Council for Education points out the importance of active learning that students actively discover and solve problems. It therefore encourages Japanese higher education to provide students with high quality education by promoting such active learning so that students are able to experience autonomous learning and acquire lifelong learning skills (Ministry of Education 2012). Cappuccio (2015) has suggested telling stories as a means of making sense of experience. He found that the digital storytelling projects could increase students' understanding of curricular content and they were willing to transform their pedagogy and curriculum to include digital storytelling. Richardson (2016) reported that seeking out scenarios where narrative pedagogies can be usefully brought into engineering teaching can provide contextualized learning, enhance student engagement and encourage deeper learning and recall. Wilujeng et al. (2017) investigated the 21 teachers implemented the storytelling in 21 different subjects towards 11 study programs. They found (1) respect different opinions, perspectives and values, (2) presentation skills and (3) ability to generate creative ideas.

In the previous studies, we have identified the possibility of active learning for enhancing problem solving skills and nurturing active thinking in the classroom by applying the activities of self-evaluation, mutual assessment and revision in a task (Miyaji 2006). One of our studies reported that the third year university students enhanced their problem solving skills in an experimental course called 'Creating Storytelling'. In this program, they were required to create stories about themselves in order to closely observe and understand who they were. Furthermore, in the process of creating the stories evaluation and revision activities were applied (Miyaji 2010, 2011, 2012). Our another study showed the effectiveness of a task to create PowerPoint slides to introduce commodities in the classroom. It aimed not only to enhance students' computer skills but also develop their expressive skills, project planning technique and proposal ability (Miyaji 2015a, Miyaji 2015b, Miyaji 2016a).

Following this task, which consisted of seven lessons in total, we provided students with another seven lessons to create slides for book recommendation, which is the main data of this paper. This time, the structure of the course applied active learning so that they must have actively participated in the task in the classroom. They created slides to inform books they are interested in by using animations and narrations. Later on, they watched all the slides in the class, evaluated and commented with each other. Based on the evaluation from other students and the teacher's feedback, they revised the slides and watched them again. By actively conducting evaluation and revision in interaction with others, the course attempted to raise their awareness towards various skills necessary for problem solving and to nurture active thinking.

This paper firstly explains the course content and titles of books recommended. Secondly we will analyze the response data of survey and discuss the results. We will report awareness-raising towards skills acquired, classifying students according to principal components in rating scale values of awareness, and extraction of major items in each group by discriminant analysis. We will also demonstrate the difference in the results between these 
two tasks (introducing commodities and books).

\section{Class Contents and Plan}

The course in this study is categorized in subjects of Information Technology (see Table 1), which is a compulsory subject for the third year students in A university. Students were required to choose one theme from three and the course was conducted according to the selected theme for 15 times ( 90 minutes per lesson). The number of the students who enrolled our course was 26, about one third of the whole third year students. The students consist of 25 males and one female. In this course, students were required to create two different slides to introduce commodities and books (see Table 1 for the course procedure). The former seven lessons were for product recommendation and the latter seven for book recommendation. Slide observation and evaluation were conducted twice and revision was undertaken once throughout the tasks (Miyaji 2015).

In this paper, we only focus on the latter task: book recommendation. The objectives of this course were (1) to acquire computer knowledge by actually using computers and (2) to make use of such knowledge in practice. It also aimed to introduce books they were moved and found interesting and useful to recommend others to read them. Students created six slides consisting of book information, summary, reasons why they recommend, tips for reading and related books. They had to use animations for easy understanding and recorded narrations in the slides. Through all of these processes, they were able to acquire writing skills and expressive skills by using pictures and diagrams. In this way, the purposes of the program were to raise students' awareness towards various skills necessary for problem solving and to nurture active thinking by applying evaluation activities in the creative task.

In this task, students had to consider how to recommend a book in an attractive way, including the way of explaining the book and how to insert visual images and photos such as cover pages. The course encouraged students to learn (1) how to express their thoughts and feelings towards the books by writing, images, animations and narrations and (2) how to encourage others to read the books they like. The course does not end by merely creating slides; students observe all the slides, evaluate each other and revise them.

In the first lesson, a 39-page booklet to explain the course objective, content, schedule, how to make slides and the way of experiment was distributed to the students. How to use animation and to record narration are already explained at the second and third lesson respectively. An image sheet for book recommendation was also provided in the seventh lesson. Students were required to explain the contents of books for recommendation at the right page of the sheet, draw a figure at the left page and bring it for the next lesson. In the eighth lesson, we made students to create slides. Later, students added animations in their slides. In the tenth lesson, students recorded narrations and completed the book recommendation slides. They submitted the files to an e-learning and we combined them into one file. In the eleventh lesson, students watched all the slides in the classroom for evaluation. The evaluation results were written on the assessment sheets and the files of the sheet were collected to the e-learning at the end of the class. We combined them into one file and uploaded it to the e-learning. After downloading it, they revised their slides according to the evaluation results and the feedback. In the following twelfth lesson they again watched the 


\section{Macrothink}

revised slides and assessed them again. The evaluation sheets were collected at the end of the class.

Students wrote final reports. They submitted one-third each on the previous days of the eleventh, twelfth and thirteenth lessons. They were returned with the teacher's comments within the lessons. They then revised and submitted the reports at the thirteenth lesson. They also filled in and submitted all the evaluation sheets. Some students who could not complete the reports and the sheets completed them at fourteenth lesson.

Table 2 shows the titles of books recommended by students in this task. It is seen that most of them were novels.

Table 1. Class plan

\begin{tabular}{|c|c|c|}
\hline Tim e & C lass plan & P lan re lated to assignm ent \\
\hline 8 & Creating slides to introduce books & $\begin{array}{l}\text { Subm ission of the entry form, creating slide, com pletion } \\
\text { of the report }\end{array}$ \\
\hline 9 & " & C reating slide, putting the an m ation \\
\hline 10 & " & C reating slide, recording narration, w riting report 1 \\
\hline 11 & $\begin{array}{l}\text { Evaluation and correction of slides to } \\
\text { introduce books }\end{array}$ & $\begin{array}{l}\text { M utual evaluation, inputting evaluation sheet } 2 \text {, m odifying } \\
\text { slide, w riting report } 2\end{array}$ \\
\hline 12 & $\begin{array}{l}\text { Evaluation of slides to introduce books and } \\
\text { report }\end{array}$ & $\begin{array}{l}\text { M utual evaluation, inputting evaluation sheet } 3 \text {, w riting } \\
\text { report } 3\end{array}$ \\
\hline 13 & $\begin{array}{l}\text { Completion of the report and the evaluation } \\
\text { sheet to introduce books }\end{array}$ & Com pleting report and evaluation sheet \\
\hline 14 & $\prime \prime$ & Com pleting report to introduce books \\
\hline
\end{tabular}


Table 2. Titles of Books Recommended by Students

\begin{tabular}{|c|c|}
\hline C ategory & T itle of a book \\
\hline \multirow{3}{*}{ Culture } & W ay of life called "Nobita" \\
\hline & The Japanese m ysterious exploration \\
\hline & Bushido - The best fam ous book to read in living language \\
\hline \multirow{3}{*}{ H obby } & To fix the heart \\
\hline & To cure a disease on ly $w$ ith vegetables \\
\hline & Unprecedented m uscular w orkout \\
\hline \multirow{9}{*}{$\begin{array}{c}\text { M ystery } \\
\text { nove } 1\end{array}$} & The sum m er when the sunflow er does not bloom \\
\hline & Confession \\
\hline & Confession \\
\hline & Puzzle \\
\hline & G bry of team B atista \\
\hline & M under of the ten angles building \\
\hline & C hildren \\
\hline & Sherbet \\
\hline & Case book of allaround valuer $\mathrm{Q}$ \\
\hline \multirow{4}{*}{$\begin{array}{c}\text { Fantasy } \\
\text { nove } 1\end{array}$} & 12 nationalh istories \\
\hline & B ond of the m eteor \\
\hline & Person who protects an apparition of a living person \\
\hline & K ing of the deer \\
\hline \multirow{9}{*}{$\begin{array}{c}\text { M odem } \\
\text { nove } 1\end{array}$} & B ookshe if of D an tarian \\
\hline & Thunderbolt \\
\hline & The Catcher in the Rye \\
\hline & 5 centim eters per second \\
\hline & 700 days war of us and residence police offic er \\
\hline & B attery \\
\hline & W e are group of bubble entrance \\
\hline & The elephant which grants a dream \\
\hline & Special law Artic le 001 DUST \\
\hline
\end{tabular}

Types of media used in the class are explanation of lecture content, slides for explaining it, lecture slides, textbook, sheet of exercise, quiz, explanation slides of a quiz given at the previous week as review, lecture note, sheets explaining handouts of how to make slides and what to include in them, slide frame for introducing the latest topics on AI, evaluation sheet file and e-learning. E-learning contents are (1) viewing of presentation slides for introducing the latest topics on AI, (2) download of presentation slides for introducing the latest topics, (3) upload of files relating to a final task, (4) bulletin board and (5) mail. Downloaded files of (2) are explanation of lecture content, handouts of how to make slides and what to include in them, evaluation sheet, frame of presentation slides and summary of peer evaluation about slides. Uploaded files of (3) are evaluation sheet (4 times) and presentation slides (2 times).

\section{Analysis and Results}

In order to understand the effectiveness of learning in creating slides for book recommendation explained in the previous section, we conduct several studies. Firstly, students are required to write down how long it takes for each activity in a task on the cover pages of their final reports, based on the idea that the basis of learning is to make time for studying. Secondly, we analyze the length of narrations and calculate time necessary for observing the slides. Thirdly, by comparing their awareness towards the acquired skills before and after the task we attempt to see the achievement level of the course objective. Fourthly, by classifying students into several groups after conducting principal component analysis 
using elongation of rating scale value of the awareness, we attempt to identify the characteristic of each group.

In this paper, it is considered that a significant difference is observed if a significance level is $5 \%$. Signs such as 'm', 'SD', 't', 'p' signify 'mean', 'standard deviation', 'test statistics' and 'significance probability' respectively. Significance levels of $0.1 \%, 1 \%, 5 \%$ and $10 \%$ are shown as $* * *, * *, *,+$ respectively.

\subsection{The Length of Time in Each Stage}

Students were required to specify how long it took to complete each activity in a task including book research, creating slides and writing final reports on the cover pages of the final reports. The results are shown on Table 3. The average time relating to slide creation was 15.8 hours including 5-hour lesson. This means that students spent about 11 hours outside the classroom.

Comparing the time spent for product recommendation slides with the one for book recommendation by a test of significance, the total time of three steps showed significance. In consequence, the time consumed by the second task was shorter than the first task.

The length of time consumed for each step in both product and book recommendations were also analyzed by the test of significance. The result showed that there was significance, meaning that the research time for book recommendation was shorter than the one for product recommendation.

These results prove that students spent less time in the second task due to the fact that they already experienced all the procedures through the first task.

Table 3. Time consumed for each step (hour)

\begin{tabular}{|l|c|c|c|c|c|c|c|c|}
\hline \multirow{2}{*}{ K ind of required tim e } & \multicolumn{2}{|c|}{ First W ork } & \multicolumn{3}{|c|}{ Second W ork } & D ifference & \multicolumn{2}{|c|}{ t- test } \\
\cline { 2 - 10 } & $\mathrm{m}$ & $\mathrm{SD}$ & $\mathrm{m}$ & $\mathrm{SD}$ & $\mathrm{m}$ & $\mathrm{SD}$ & $\mathrm{t}$ & $\mathrm{p}$ \\
\hline C o lecting inform ation & 5.1 & 2.7 & 3.3 & 2.1 & 1.7 & 2.1 & 4.4 & $* * *$ \\
\hline C reating slides & 6.8 & 2.8 & 5.8 & 2.9 & 1.0 & 3.1 & 1.6 & \\
\hline W riting finalreports & 7.4 & 3.2 & 6.7 & 2.9 & 0.8 & 2.8 & 1.4 & \\
\hline \multicolumn{1}{|c|}{ Total } & 19.3 & 5.7 & 15.8 & 5.7 & 3.5 & 4.9 & 3.7 & $* *$ \\
\hline
\end{tabular}

\subsection{Length of Narrations and the Number of Letters and Figures}

26 students submitted the slide files. Each of them took two minutes for watching and it took a minute for other student's evaluation. The length of narrations is shown in Table 4. The total length for six slides was 100.7 seconds. By limiting the number of slides, the average time for presentation was about 1.68 minutes. The maximum length was 167 seconds whereas the minimum was 33 seconds. Most of the slides took almost 2 minutes, which were the limit of the presentation time. The total time for watching and assessing was thus about 70 minutes.

We conducted tests of significance with regard to the narration time of the first and second tasks, the number of letters for narrations and the number of figures used in the slides. All the 
results showed significance, showing that all the items in the second task were smaller than those in the first task. Students used a number of figures in introducing products in order to compare what they introduced with other products whereas in book recommendation they merely used cover pages of the books as the primary visual images.

Table 4. The Length of narrations and the number of letters and figures

\begin{tabular}{|l|r|r|r|r|r|r|r|r|}
\hline \multirow{2}{*}{ Contents } & \multicolumn{2}{|c|}{ First W ork } & \multicolumn{2}{|c|}{ Second W ork } & \multicolumn{2}{|c|}{ D ifference } & \multicolumn{2}{|c|}{-test } \\
\cline { 2 - 10 } & \multicolumn{1}{c|}{$\mathrm{m}$} & \multicolumn{1}{c|}{$\mathrm{SD}$} & \multicolumn{1}{c|}{$\mathrm{m}$} & \multicolumn{1}{c|}{$\mathrm{SD}$} & \multicolumn{1}{c|}{$\mathrm{m}$} & $\mathrm{SD}$ & $\mathrm{t}$ & $\mathrm{p}$ \\
\hline Narration (sec) & 124.2 & 36.1 & 100.7 & 28.0 & 23.5 & 31.8 & 3.7 & $* * *$ \\
\hline No. of letters & 539.8 & 193.3 & 441.3 & 113.5 & 98.5 & 152.4 & 3.2 & $* * *$ \\
\hline No. of figures & 12.2 & 6.5 & 6.0 & 2.3 & 6.2 & 6.3 & 4.9 & $* * *$ \\
\hline
\end{tabular}

\subsection{Awareness-Raising towards Skills Acquired}

Students were required to fill in evaluation sheets concerning their awareness towards skills on the first (pre) and the last (post) lessons (see Table 5). Nine-evaluation scale includes (1) not at all; (3) slightly acquired; (5) acquired a little; (7) acquired a lot and (9) very much acquired. The number of participants was 26. The average rating of 30 items concerning the awareness towards skills before and after the task was analyzed by the test of significance. The result showed that the significance level was $0.1 \%$, showing significance $\left(\mathrm{t}(779)=4.1^{* * *}\right.$, $\mathrm{p}<0.001)$. This means that students thought that their awareness towards skills was raised as a whole.

After analyzing the average rating of each item relating to skills before and after the task, all 30 items had significance. This means that students felt that all the awareness towards skills were developed more than before. This proves that the course was effective in enhancing awareness towards problem solving skills and self-satisfaction.

The result in Table 5 shows that (1) interests towards computers; (2) understanding of computers; (3) computer skills and (4) usages of computers in other fields were developed. This means that one of the course objectives, to equip with computer knowledge, was achieved although it was in the awareness level.

By making book recommendation slides, students nurtured expressive skills in writing by explaining books and writing final reports as well as acquired skills of using non-linguistic devices by inserting visual images and photos relating to the books. Acquiring various skills and raising awareness necessary for problem solving are both developed significantly (see Table 5), showing that the course objective was achieved in the consciousness level.

The development of all 30 items in the first and second tasks was analyzed by the test of significance. The result didn't show significance. This means that although the awareness rose after the tasks, there was no difference between them. Pairs of ratings before and after the task for the first and second tasks were $(4.1,5.1)$ and $(4.8,5.7)$. 
Table 5. Results of tests of significance concerning the awareness towards skills

\begin{tabular}{|c|c|c|c|c|c|c|c|c|c|c|c|c|}
\hline \multirow[t]{2}{*}{ Evaluation Item s } & \multicolumn{4}{|c|}{ First W ork } & \multicolumn{4}{|c|}{ Second W ork } & \multicolumn{4}{|c|}{$\begin{array}{l}\text { D ifference of } \\
\text { Rating Value }\end{array}$} \\
\hline & $\mathrm{m}$ & $\mathrm{SD}$ & $\mathrm{t}$ & $\mathrm{p}$ & $\mathrm{m}$ & SD & $\mathrm{t}$ & $\mathrm{p}$ & \begin{tabular}{l|l}
$\mathrm{m}$ & \\
\end{tabular} & \begin{tabular}{|l|l|}
$\mathrm{SD}$ \\
\end{tabular} & $\mathrm{t}$ & $\mathrm{p}$ \\
\hline (1) In terest in and curiosity about com puters & 0.9 & 1.2 & 3.6 & $* *$ & 0.7 & 1.0 & 3.3 & $* *$ & 0.2 & 1.0 & 1.2 & \\
\hline (2) Understanding of com puters & 1.3 & 1.5 & 4.6 & $* * *$ & 1.2 & 1.2 & 4.9 & $* * *$ & 0.1 & \begin{tabular}{|l|l|}
1.9 \\
\end{tabular} & 0.3 & \\
\hline (3) C om puter operation skills & 1.3 & 1.0 & 6.2 & $* * *$ & 0.9 & 0.9 & 5.0 & $* * *$ & 0.3 & 1.2 & 1.4 & \\
\hline (4) C om puter usage $m$ ethods and broaden ing of situations & 1.0 & 0.9 & 5.1 & $* * *$ & 1.1 & 1.1 & 5.0 & $* * *$ & -0.1 & 1.0 & 0.5 & \\
\hline (5) Ability to set challenges, ability to discover problem s & 1.1 & 0.9 & 6.3 & $* * *$ & 0.9 & 0.9 & 5.3 & $* * *$ & 0.2 & 1.2 & 0.8 & \\
\hline (6) Ability to plan, to do things in a planned m anner & 1.2 & 1.2 & 4.7 & $* * *$ & 0.9 & 1.0 & 4.2 & $* * *$ & 0.3 & 1.7 & 0.8 & \\
\hline (7) Cultivation of understanding of know ledge leamed & 1.3 & 1.3 & 5.3 & $* * *$ & 1.1 & 1.3 & 4.1 & $* * *$ & 0.3 & \begin{tabular}{|l|l|}
1.8 \\
\end{tabular} & 0.7 & \\
\hline (8) Ability to study by onese lf, ability to leam & 1.0 & 1.2 & 4.0 & $* * *$ & 1.2 & 1.3 & 4.7 & $* * *$ & -0.2 & 1.5 & 0.8 & \\
\hline (9) Ability to gather inform ation, ability to conduct research & 1.3 & 1.6 & 4.1 & $* * *$ & 1.0 & 1.2 & 4.5 & $* * *$ & 0.2 & 1.7 & 0.7 & \\
\hline (10) Ability to sort through re ated inform ation or data & 1.3 & 1.3 & 5.2 & $* * *$ & 1.0 & 1.2 & 4.5 & $* * *$ & 0.3 & 1.6 & 0.9 & \\
\hline (11) Ability to analyse inform ation & 0.8 & 0.8 & 5.2 & $* * *$ & 1.0 & 1.1 & 4.6 & $* * *$ & -0.2 & 1.0 & 0.9 & \\
\hline (12) Ability to express thoughts in w riting & 1.2 & 1.0 & 6.1 & $* * *$ & 0.8 & 1.0 & 4.0 & $* * *$ & 0.5 & 1.0 & 2.4 & * \\
\hline (13) Ability to express thoughts through m edia other than w riting & 1.3 & 1.3 & 5.2 & $* * *$ & 0.8 & 1.1 & 3.4 & $* *$ & 0.5 & 1.6 & 1.6 & \\
\hline (14) Ability to tak to and explain to others com prehensively & 1.3 & 1.1 & 6.1 & $* * *$ & 0.9 & 1.0 & 4.5 & $* * *$ & 0.5 & 1.3 & 1.8 & + \\
\hline (15) Ability to $m$ ake presentations & 1.4 & 1.2 & 5.6 & $* * *$ & 0.7 & 0.9 & 3.9 & $* * *$ & 0.7 & 1.5 & 2.2 & * \\
\hline (16) Ability to listen to others and to ask questions to others & 0.7 & 0.9 & 4.3 & $* * *$ & 0.8 & 1.0 & 4.2 & $* * *$ & -0.1 & 1.1 & 0.4 & \\
\hline (17) Com m unication ability & 0.7 & 0.8 & 4.5 & $* * *$ & 0.9 & 1.2 & 3.8 & $* * *$ & -0.2 & 1.4 & 0.7 & \\
\hline (18) Ability to appropriately self-evaluate one's thoughts & 1.0 & 1.1 & 4.3 & $* * *$ & 1.0 & 1.2 & 4.5 & $* * *$ & -0.1 & 1.5 & 0.3 & \\
\hline (19) Ability to appropriately evaluate other people's thoughts & 0.7 & 1.1 & 3.5 & $* *$ & 0.7 & 0.9 & 3.8 & $* * *$ & 0.0 & 1.4 & 0.1 & \\
\hline (20) Ability to correct and im prove on one's ow $n$ thoughts & 0.8 & 1.0 & 4.2 & $* * *$ & 0.9 & 1.0 & 4.8 & $* * *$ & -0.1 & 1.3 & 0.4 & \\
\hline (21) Ability to pursue m atters deeply, ability to explore m atters & 0.7 & 0.9 & 4.3 & $* * *$ & 0.8 & 1.1 & 3.5 & $* *$ & 0.0 & 1.3 & 0.1 & \\
\hline (22) Ability to execute, ability to practice, ability to put in to action & 0.7 & 0.9 & 4.1 & $* * *$ & 0.7 & 0.9 & 3.9 & $* * *$ & 0.0 & 1.0 & 0.0 & \\
\hline (23) Ability to cooperate and to leam concertedly & 0.7 & 1.3 & 2.7 & * & 1.0 & 1.2 & 4.1 & $* * *$ & -0.3 & 1.3 & 1.0 & \\
\hline (24) Sense of accom plishm ent, sense of satisfaction & 1.0 & 1.2 & 3.9 & $* * *$ & 1.2 & 1.5 & 4.0 & $* * *$ & -0.2 & 2.0 & 0.5 & \\
\hline (25) Sense of fulfim ent, sense of ach ievem ent & 0.8 & 1.1 & 3.9 & $* * *$ & 1.4 & 1.4 & 4.8 & $* * *$ & -0.5 & 1.7 & 1.5 & \\
\hline (26) Ability to solve problem s & 0.8 & 0.9 & 4.4 & $* * *$ & 0.9 & 1.0 & 4.6 & $* * *$ & -0.1 & 1.5 & 0.4 & \\
\hline (27) Ability to construct and create know ledge & 0.8 & 1.0 & 4.1 & $* * *$ & 0.6 & 0.9 & 3.1 & $* *$ & 0.3 & 1.3 & 1.0 & \\
\hline (28) Ability to think, consider and com e up w ith ideas by onese ff & 1.0 & 1.2 & 4.5 & $* * *$ & 0.8 & 1.2 & 3.3 & $* *$ & 0.2 & 1.6 & 0.7 & \\
\hline (29) C reativity/ability to create & 0.8 & 1.2 & 3.6 & $* *$ & 1.2 & 1.1 & 5.3 & $* * *$ & -0.3 & 1.6 & 1.0 & \\
\hline (30) Interest in and curiosity about th is fie $\mathrm{d}$ & 0.8 & 1.2 & 3.5 & $* *$ & 0.7 & 1.2 & 3.1 & $* *$ & 0.1 & 1.4 & 0.4 & \\
\hline Average & 1.0 & 1.1 & 4.4 & $* * *$ & 0.9 & 1.1 & 4.1 & $* * *$ & 0.1 & 1.5 & 1.4 & \\
\hline
\end{tabular}

The awareness-raising of each item in both tasks was also analyzed by the test of significance. The result shows that the items (12) skills to express your own ideas by writing and (15) presentation skills had significance. This means that the awareness of these items in the second task was less than that in the first task. It is also seen that the item (14) skills to explain something to others in an easy way had a tendency of significance. This means that the awareness of this item in the second task was less than that in the first task.

\subsection{Principal Component Analysis of Awareness Raising}

In order to classify students into several groups and to identify the characteristic of each group with regard to each factor, principal component analysis was conducted by means of covariance matrix to the difference between the post- and pre-task rating scale values of the awareness of 30 skills in both tasks specified in Table 6. The loadings after extraction of the principal components 1 and 2 were $38.0 \%$ and $10.5 \%$. As a result, cumulative loading of them is $48.5 \%$. Each evaluation item is displayed by coefficients of Component 1 in the matrix component in descending order.

Coefficient of evaluation items in Component 1 was $0.80 \sim 0.29$, which is considered as the total variable of all items. Therefore Component 1 can be classified as 'Total skills necessary for problem solving'. 
Table 6. Coefficients of matrix component about awareness

\begin{tabular}{|c|c|c|}
\hline Ability item s & \begin{tabular}{|l|}
$\begin{array}{c}\text { Com po } \\
\text { nent } 1\end{array}$ \\
\end{tabular} & $\begin{array}{l}\text { Com po } \\
\text { nent } 2 \\
\end{array}$ \\
\hline (8) Ability to study by onese If, ability to leam & 0.803 & 0.085 \\
\hline (27) Ability to construct and create know ledge & 0.775 & -0.027 \\
\hline (7) Cultivation of understanding of know ledge leamed & 0.767 & 0.097 \\
\hline (29) C reativity/ability to create & 0.737 & -0.108 \\
\hline (13) Ability to express thoughts through m edia other than w riting & 0.733 & -0.263 \\
\hline (24) Sense of accom plishm ent, sense of satisfaction & 0.716 & -0.519 \\
\hline (28) Ability to think, consider and com e up w ith ideas by onese ff & 0.703 & -0.196 \\
\hline (25) Sense of fulfim ent, sense of ach ievem ent & 0.685 & -0.475 \\
\hline (9) Ability to gather inform ation, ability to conduct research & 0.650 & 0.355 \\
\hline (10) Ability to sort through re ated inform ation or data & 0.642 & 0.362 \\
\hline (23) Ability to cooperate and to leam concertedly & 0.642 & -0.413 \\
\hline (12) Ability to express thoughts in w riting & 0.640 & 0.079 \\
\hline (20) Ability to correct and im prove on one's ow $n$ thoughts & 0.637 & 0.043 \\
\hline (14) Ability to tak to and explain to others com prehensively & 0.621 & 0.416 \\
\hline (18) Ability to approprately seff-evaluate one's thoughts & 0.610 & 0.367 \\
\hline (4) Com puter usage m ethods and broadening of situations & 0.610 & 0.030 \\
\hline (16) Ability to listen to others and to ask questions to others & 0.606 & 0.386 \\
\hline (21) Ability to pursue matters deeply, ability to explore m atters & 0.594 & -0.086 \\
\hline (5) Ability to set challenges, ability to discover problem s & 0.579 & 0.044 \\
\hline (1) Interest in and curiosity about com puters & 0.556 & -0.218 \\
\hline (26) Ability to so lve problem s & 0.539 & -0.105 \\
\hline (11) Ability to analyse inform ation & 0.457 & 0.585 \\
\hline (19) Ability to appropriately evaluate other people's thoughts & 0.470 & 0.556 \\
\hline (15) Ability to $m$ ake presentations & 0.451 & 0.519 \\
\hline (30) Interest in and curiosity about th is fie $\mathrm{ld}$ & 0.287 & 0.494 \\
\hline (6) Ability to plan, to do things in a planned manner & 0.466 & 0.268 \\
\hline (3) Com puter operation skills & 0.410 & 0.068 \\
\hline (17) Com m unication ability & 0.454 & 0.061 \\
\hline (22) Ability to execute, ability to practice, ability to put in to action & 0.488 & -0.244 \\
\hline (2) Understanding of com puters & 0.430 & -0.252 \\
\hline
\end{tabular}

On the other hand, coefficient of evaluation items in Component 2 was $-0.52 \sim 0.58$. High positive coefficients in Component 2 were (11) ability to analyse information, (19) ability to appropriately evaluate other people's thoughts and (15) ability to make presentations whereas high negative coefficients were (24) sense of accomplishment and (25) sense of fulfilment. Therefore the positive direction signifies 'awareness of information analysis, evaluation and presentation' and the negative direction is 'awareness of satisfaction'. It is considered that students' awareness-raising in creating book recommendation slides can be explained by these two components.

\subsection{Classifying Students According to Principal Components in Rating Scale Values of} Awareness

In order to identify the characteristic of each student group using the development of rating scale value signifying students' awareness-raising, we classified 26 students into four clusters (Group: S1-S4) by Cluster Analysis using principal component scores (see 3.4) as variables. The result is shown in Figure 1.

The number of students in $\mathrm{S} 1$ is five ( $\triangle$, see at the upper left of Figure 1). The average development is 0.94 , whose average rate is the third highest in four groups. The average growth of each student was 0.47 to 1.20 . 


\section{Macrothink}

The number of students in S2 is three ( $O$, see at the upper right of Figure 1). The average development is 2.21 , whose average rate is the highest of all. The average growth of each student was 1.73 to 2.50 . The average growth was larger than the total average, meaning that S2 showed the highest growth of awareness in four groups. This demonstrates that their computer skills have been developed in this group.

S3 consists of seven students ( $\square$, see in the bottom of Figure 1). The average growth was 1.17, which was the second highest in four groups. The average growth of each student was 0.53 to 1.67 .

S4 consists of eleven students (+, see in the middle of Figure 1). The average development was 0.42 , the lowest growth of all. This means that the total skills necessary for problem solving are the lowest. The average growth of each student is also 0.10 to 1.13 . The total skills for problem solving were not acquired much in this group.

In order to identify the characteristics of student groups, we conducted Cluster Analysis by means of Ward's method using awareness as cases and students as variables. From the dendrogram we obtained through the analysis, awareness was classified into four clusters (G1-G4). G1 consists of eight types of awareness including items (9), (10), (16), (15), (19), (11), (14) and (30). The items showing high development among them were (9) information gathering; (10) data management skills and (11) skills to analyze information so that this group can be characterized as 'awareness of skills for information gathering, management and analysis'.



Figure 1. Four student groups represented on the two-component plane 
Cluster G2 consists of seven kinds of awareness including (24) self-satisfaction; (25) self-achievement; (1) interests towards computers; (12) writing skills to explain your ideas; (21) skills to explore something deeply; (22) performance and (23) collaborative learning. Therefore this group is called 'awareness of self-satisfaction and self-achievement'.

Cluster G3 consists of six types of awareness including (7) deep understanding of knowledge; (8) autonomous learning skills; (3) computer skills; (5) task setting; (6) task planning and (4) how to use computers in broader contexts so that it is characterized as 'awareness of learning and deep understanding by using computers'.

Cluster G4 consists of nine kinds of awareness, (2) understanding of computers; (28) ability to think and produce ideas; (13) skills to express your thoughts without writing; (17) communicative competence; (26) problem solving skills; (27) ability to systematize knowledge; (20) skills to ameliorate and improve ideas; (29) creative skills and (18) selfevaluation skills towards own ideas. This group, thus, is characterized as 'awareness of understanding, creative and evaluation skills towards computers'.

The average score and standard deviation of each group is specified in Table 7. Table 8 shows the result of two factor ANOVA concerning awareness-raising of each group. As a result, interaction was significant $(\mathrm{F}(3,776)=86.6, \mathrm{p}<.001)$. Both student and awareness groups show significance. The results of multiple comparisons are shown in Table 9. All the results can be summarized according to awareness groups as follows: G1: $\mathrm{S} 2=\mathrm{S} 1>\mathrm{S} 3>\mathrm{S} 4, \mathrm{G} 3$ : $\mathrm{S} 2>\mathrm{S} 1=\mathrm{S} 3=\mathrm{S} 4, \mathrm{G} 2: \mathrm{S} 2=\mathrm{S} 3>\mathrm{S} 1>\mathrm{S} 4, \mathrm{G} 4: \mathrm{S} 2>\mathrm{S} 3>\mathrm{S} 1=\mathrm{S} 4$. Here, $\mathrm{S}_{\mathrm{m}}>\mathrm{S}_{\mathrm{n}}$ signifies that $\mathrm{S}_{\mathrm{m}}$ is significantly larger than $S_{n}$ whereas $S_{m}=S_{n}$ signifies that there is no significance between $S_{m}$ and $S_{n}$.

The results show that the student group S1 records the best growth in the awareness group G1. This means that $\mathrm{S} 1$ is the group that 'the awareness of information gathering, management and analysis' has been well raised. Concerning other awareness groups, S1 shows moderate growth.

The student group S2 shows the highest development in all awareness groups and particularly it developed G3 and G4 as the highest growth. Therefore the students in this group raised 'awareness of learning and deep understanding by using computers' and 'awareness of understanding, creative and evaluation skills towards computers'.

S3 records the highest growth in G2. Therefore the students in this group have well raised 'awareness of self-satisfaction and self-achievement'.

The student group S4 shows the lowest growth in all awareness groups. 
Table 7. Average ratings and standard deviation of each group

\begin{tabular}{|c|c|c|c|c|c|c|c|c|c|c|c|}
\hline \multirow{3}{*}{$\begin{array}{c}\text { Aw arw ness } \\
\text { G roup }\end{array}$} & $\begin{array}{l}\text { Student } \\
\text { G roup }\end{array}$ & \multicolumn{2}{|c|}{ S 1} & \multicolumn{2}{|c|}{ S 2} & \multicolumn{2}{|c|}{ S 3} & \multicolumn{2}{|c|}{ S 4} & \multicolumn{2}{|c|}{ Total } \\
\hline & $\begin{array}{c}\text { No. of } \\
\text { students }\end{array}$ & \multicolumn{2}{|c|}{5} & \multicolumn{2}{|c|}{3} & \multicolumn{2}{|c|}{7} & \multicolumn{2}{|c|}{11} & \multicolumn{2}{|c|}{26} \\
\hline & \begin{tabular}{|c|} 
No. of \\
aw areness \\
\end{tabular} & $\mathrm{m}$ & SD & $\mathrm{m}$ & SD & $\mathrm{m}$ & $\mathrm{SD}$ & $\mathrm{m}$ & SD & $\mathrm{m}$ & SD \\
\hline G 1 & 8 & 1.55 & 0.97 & 2.17 & 0.85 & 0.63 & 1.09 & 0.36 & 0.59 & 0.87 & 1.07 \\
\hline $\mathrm{G} 2$ & 7 & 0.43 & 0.77 & 2.33 & 1.28 & 1.69 & 1.18 & 0.26 & 0.54 & 0.92 & 1.19 \\
\hline G 3 & 6 & 1.03 & 1.14 & 2.50 & 0.76 & 0.98 & 1.10 & 0.62 & 0.77 & 1.01 & 1.10 \\
\hline $\mathrm{G} 4$ & 9 & 0.73 & 0.88 & 1.96 & 0.84 & 1.38 & 1.31 & 0.44 & 0.83 & 0.93 & 1.13 \\
\hline Total & 30 & 0.94 & 1.03 & 2.21 & 0.97 & 1.17 & 1.25 & 0.42 & 0.71 & 0.93 & 1.12 \\
\hline
\end{tabular}

Table 8 . The result of analysis of variance concerning awareness-raising of each group

\begin{tabular}{|c|c|c|c|c|c|}
\hline Contributing factor & $\begin{array}{l}\text { Sum of } \\
\text { squares }\end{array}$ & $\begin{array}{l}\text { D egree of } \\
\text { freedom }\end{array}$ & $\begin{array}{c}\text { M ean } \\
\text { square }\end{array}$ & $F$ & $\mathrm{p}$ \\
\hline Student G roup & 246.0 & 3 & 82.0 & 93.5 & $* * *$ \\
\hline Aw areness Group & 1.8 & 3 & 0.6 & 0.7 & \\
\hline Student XAw areness & 67.4 & 9 & 7.5 & 8.5 & $* * *$ \\
\hline Error & 670.2 & 764 & 0.9 & & \\
\hline Total & 986.8 & 779 & & & \\
\hline
\end{tabular}

Table 9. Multiple comparisons of awareness-raising of each group

\begin{tabular}{|c|c|c|c|c|c|c|}
\hline G roup & S1 S2 & S1 S3 & S 1 S4 & S2 S3 & S2 S4 & S 3 S4 \\
\hline G 1 & & $>$ & $>$ & $>$ & $>$ & \\
\hline G 2 & \langle & \langle & & & $>$ & $>$ \\
\hline G 3 & \langle & & & $>$ & $>$ & \\
\hline G 4 & \langle & \langle & & $>$ & $>$ & $>$ \\
\hline
\end{tabular}

\subsection{Extraction of Major Items in Each Group by Discriminant Function Analysis}

In order to identify major items for each student group, we conducted Discriminant Function Analysis by using the development of rating score values of awareness.

\subsubsection{Items of Awareness Contributing Discrimination}

After Discriminant Function Analysis of the development of rating score values of awareness in student groups S1-S4, we found that there were three discriminant functions whose fixed values were 111.1, 96.9 and 6.3 respectively. The first discriminant function 1 possesses $51.9 \%$ of information so that canonical discriminant function coefficients of this discriminant function 1 should be investigated.

Concerning discriminant function 1, the types of awareness whose standardized canonical discriminant function coefficients are positively high were (4) how to use computers in broader contexts, (22) performance and (20) skills to ameliorate and improve ideas. These kinds of awareness signify the 'awareness of skills to pursue something by using computer 
skills and knowledge, explaining and ameliorating'.

Awareness of high negative canonical discriminant function coefficients includes (1) interests towards computers, (5) task setting and (18) self-evaluation skills towards own ideas. These are the types of 'awareness of having interests towards computers, setting a task and evaluating'. These kinds of awareness strongly contribute to discrimination.

\subsubsection{Major Items of Awareness in Each Group}

Among Fisher's Discrimination Function, the average score of awareness-raising of S1 in the previous section shows that the scores of about a half of awareness were higher than the total average score, including 14 important items as shown in Table 10: (4), (6), (7), (9), (10), (11), (12), (14), (15), (16), (18), (19), (20) and (30). The average rise of awareness was 0.94. Because all the items in G1 were important for this group, it is said that students in S1 have raised 'awareness of information gathering, management and analysis'. Concerning other types of awareness, the development was moderate, which was the same result as the one in 3.5.

In terms of the average score of awareness-raising of S2, 29 items were higher than the total average except the item (2) as shown in Table 10. The average score was 2.21, which shows that students in S2 raised their awareness the most. The scores of all groups (G1-G4) are higher than the total average score. In consequence, the students in S2 have raised 'awareness of information gathering, management and analysis', 'awareness of self-satisfaction and self-achievement', 'awareness of learning and deep understanding by using computers' and 'awareness of understanding, creative and evaluation skills towards computers'.

Concerning the average score of awareness-raising of S3, the scores of about a half of items (in total 18) including (1), (2), (4), (7), (12), (13), (16), (17), (20), (21), (22), (23), (24), (25), (26), (27), (28) and (29) were higher than the total average score as shown in Table 10. It also shows that all the items in G2 and 8 out of 9 items in G4 were considered as important. As a result, students in S3 have raised 'awareness of self-satisfaction and self-achievement' and 'awareness of understanding, creative and evaluation skills towards computers'.

The average scores of awareness-raising of S4 were lower than the total average in all awareness groups, showing that there was no item as important as shown in Table 10. 
Table 10. Important items of awareness in each student group

\begin{tabular}{|c|c|c|c|c|c|c|c|c|c|c|c|}
\hline \multirow{2}{*}{$\begin{array}{c}\text { Aw areness } \\
\text { G roup }\end{array}$} & \multirow[t]{2}{*}{ Student Group } & \multicolumn{2}{|c|}{ S1 } & \multicolumn{2}{|c|}{ S2 } & \multicolumn{2}{|c|}{ S3 } & \multicolumn{2}{|c|}{ S4 } & \multicolumn{2}{|c|}{ Total } \\
\hline & & $\mathrm{m}$ & $\mathrm{SD}$ & $\mathrm{m}$ & $\mathrm{SD}$ & $\mathrm{m}$ & SD & $\mathrm{m}$ & $\mathrm{SD}$ & $\mathrm{m}$ & $\mathrm{SD}$ \\
\hline \multirow{8}{*}{ G 1} & (9) Ability to gather inform ation, ability to conduct research & 1.4 & 1.3 & 2.3 & 0.6 & 1.0 & 1.5 & 0.5 & 0.7 & 1.0 & 1.2 \\
\hline & (10) Ability to sort through re hated inform ation or data & 1.8 & 1.1 & 2.3 & 0.6 & 1.0 & 1.5 & 0.4 & 0.5 & 1.0 & 1.2 \\
\hline & (16) Ability to listen to others and to ask questions to others & 1.4 & 0.9 & 1.7 & 1.5 & 0.9 & 1.1 & 0.3 & 0.5 & 0.8 & 1.0 \\
\hline & (15) Ability to $m$ ake presentations & 1.4 & 0.9 & 2.3 & 0.6 & 0.3 & 0.8 & 0.3 & 0.5 & 0.7 & 1.0 \\
\hline & (19) Ability to approprately evaluate other people's thoughts & 1.6 & 0.9 & 2.0 & 0.0 & 0.3 & 0.8 & 0.2 & 0.4 & 0.7 & 0.9 \\
\hline & (11) Ability to analyse inform ation & 1.8 & 1.5 & 2.3 & 0.6 & 0.7 & 1.0 & 0.5 & 0.8 & 1.0 & 1.1 \\
\hline & (14) Ability to tak to and exphin to others com prehensive $y$ & 1.4 & 0.9 & 2.3 & 0.6 & 0.9 & 0.9 & 0.3 & 0.6 & 0.9 & 1.0 \\
\hline & (30) Interest in and curiosity about th is fie ld & 1.6 & 0.9 & 2.0 & 2.0 & 0.0 & 1.2 & 0.5 & 0.7 & 0.7 & 1.2 \\
\hline \multirow{7}{*}{ G 2} & (24) Sense of accom plishm ent, sense of satisfaction & 0.0 & 0.0 & 3.0 & 1.7 & 2.6 & 1.0 & 0.3 & 0.6 & 1.2 & 1.5 \\
\hline & (25) Sense of fulfim ent, sense of achievem ent & 0.4 & 0.9 & 3.7 & 1.5 & 2.4 & 0.8 & 0.5 & 0.8 & 1.4 & 1.5 \\
\hline & (1) Interest in and curiosity about com puters & 0.6 & 0.9 & 1.0 & 1.0 & 1.3 & 1.5 & 0.2 & 0.4 & 0.7 & 1.0 \\
\hline & (12) Ability to express thoughts in w riting & 1.0 & 1.0 & 1.7 & 1.5 & 1.3 & 1.0 & 0.1 & 0.3 & 0.8 & 1.0 \\
\hline & (21) Ability to pursue matters deeply, ability to expbre m atters & 0.2 & 0.4 & 3.0 & 1.0 & 1. 0 & 1.0 & 0.3 & 0.5 & 0.8 & 1.1 \\
\hline & (22) Ability to execute, ability to practice, ability to put into action & 0.4 & 0.9 & 2.0 & 0.0 & 1.1 & 1.1 & 0.3 & 0.6 & 0.7 & 1.0 \\
\hline & (23) Ability to cooperate and to leam concertedly & 0.4 & 0.9 & 2.0 & 0.0 & 2.1 & 1.2 & 0.2 & 0.4 & 1.0 & 1.2 \\
\hline \multirow{6}{*}{ G 3} & (7) Cultivation of understanding of know ledge leamed & 1.4 & 1.3 & 3.0 & 1.0 & 1.1 & 1.6 & 0.4 & 0.7 & 1.1 & 1.4 \\
\hline & (8) Ability to study by onese If, ability to leam & 1.0 & 1.4 & 3.7 & 0.6 & 1.1 & 0.9 & 0.6 & 0.8 & 1.2 & 1.3 \\
\hline & (3) C om puter operation skills & 0.8 & 1.1 & 2.0 & 0.0 & 0.7 & 1.0 & 0.8 & 0.9 & 0.9 & 0.9 \\
\hline & (5) Ability to set challenges, ability to discover problem s & 0.8 & 1.1 & 2.0 & 0.0 & 0.9 & 0.9 & 0.7 & 0.8 & 0.9 & 0.9 \\
\hline & (6) Ability to plan, to do things in a planned $m$ anner & 1.0 & 1.4 & 2.3 & 0.6 & 0.4 & 0.8 & 0.7 & 0.9 & 0.9 & 1.1 \\
\hline & (4) Com puter usage m ethods and broadening of situations & 1.2 & 1.1 & 2.0 & 0.0 & 1.6 & 1.4 & 0.5 & 0.7 & 1.1 & 1.1 \\
\hline \multirow{10}{*}{ G 4} & (2) Understanding of com puters & 1.0 & 1.0 & 1.0 & 1.0 & 2.0 & 1.5 & 0.9 & 1.2 & 1.2 & 1.3 \\
\hline & (28) Ability to think, consider and com e up w ith ideas by onese ff & 0.0 & 0.0 & 2.0 & 0.0 & 1.4 & 1.5 & 0.5 & 1.2 & 0.8 & 1.3 \\
\hline & (13) Ability to express thoughts through $m$ edia other than w riting & 0.2 & 0.4 & 1.7 & 1.5 & 1.9 & 1.2 & 0.1 & 0.3 & 0.8 & 1.1 \\
\hline & (17) C om m un ication ability & 0.6 & 0.9 & 1.7 & 1.5 & 1.3 & 1.7 & 0.6 & 0.9 & 0.9 & 1.2 \\
\hline & (26) Ability to solve problem s & 0.6 & 0.9 & 2.3 & 0.6 & 1.1 & 1.1 & 0.5 & 0.8 & 0.9 & 1.0 \\
\hline & (27) Ability to construct and create know ledge & 0.2 & 0.4 & 2.3 & 0.6 & 0.9 & 1.1 & 0.1 & 0.3 & 0.6 & 0.9 \\
\hline & (20) Ability to correct and in prove on one's ow $n$ though ts & 1.2 & 1.1 & 2.0 & 0.0 & 1.1 & 1.1 & 0.4 & 0.7 & 0.9 & 1.0 \\
\hline & (29) C reativity/ability to create & 1.0 & 1.0 & 2.3 & 0.6 & 1.9 & 1.2 & 0.5 & 0.7 & 1.2 & 1.1 \\
\hline & (18) Ability to approprately se ff-evaluate one's thoughts & 1.8 & 0.4 & 2.3 & 0.6 & 0.9 & 1.6 & 0.5 & 0.8 & 1.0 & 1.2 \\
\hline & Average & 0.9 & 0.5 & 2.2 & 0.6 & 1.2 & 0.6 & 0.4 & 0.2 & 0.9 & 0.2 \\
\hline
\end{tabular}

\section{Consideration and Discussion}

\subsection{The Length of Time in Each Stage}

Creating the slide (the second work) to introduce the book was compared with creating the slide (the first work) to introduce the product by significance test. As a result, it is found that the required time of the second work was shorter than that of the first work. In addition, the time in each of the first work and the second work was compared by significance test about every stage of time. As a result, it is showed that the investigation time in the second work was shorter than that of the first work. Because students experienced creating the first work from these, investigation time shortened, and it is deduced that the time required of the second work shortened as a whole.

\subsection{Length of Narrations and the Number of Letters and Figures}

It was shown that length of narrations, the number of letters and the number of the figure which students used in a slide were smaller in the second work than those in the first work. Even though students were beforehand instructed to record narration of slides within two minutes, there were several first works which had longer narration time than two minutes. For this, time to watch the works of all the members has exceeded 90 minutes of a school hour for about 10 minutes. Therefore I ordered students to create them so that narration time of the second work again was not over two minutes. As a result, the narration time for second work became shorter than that for the first work. With shortening narration time, it is suggested that 
the text length of the narration decreased. As one of the reasons, the image figures were not only used to show production but also a lot of figures were presented to introduce the other brands. In addition, in the case of a book, it is thought that there may be few figure it because the image of the cover is important as a figure.

\subsection{Awareness-Raising towards Skills Acquired}

All awareness relating to skills (1) - (30) was recognized to have significant difference as explained in section 3.3. As the reason for enhanced awareness, it is considered that it was possible to enhance various skills by different kinds of activities during and outside of classes.

Miyaji (2016b) has reported useful activities for improving awareness as the following. It is shown that Group 1 'Activities concerning asking a question or narrations' is useful for students' raising Category II 'Awareness relating to listening and evaluation'. This is explained by a little more concrete content as follows. Activities, 'To hear friends about the experiment content', 'to put the animation on slides', 'to put the narration into slides', 'to evaluate presentation slides by oneself', 'to evaluate presentation slides of others', 'to correct presentation slide', 'to correct a part of the report which a teacher pointed out', and so on, raise abilities 'to communicate', 'to co-operate and to learn concertedly', 'to listen to others and to raise questions to others', 'to evaluate properly what has been figured out by others', and 'to self-evaluate properly what is figured out by oneself'.

It is also seen that Group 2, 'Activities relating to slide creation' is useful for raising Category I 'Awareness concerning task setting, deep understanding and interest'. This is explained by a little more concrete content as follows. Activities, 'To hear a description of the experiment content', 'To have an image of the entire experiment', 'To find out about the contents of book', 'To organize for the others to understand what to be examined', 'To decide the title of book', 'To create explanation, 'To create book presentation slides', 'To write a report' and so on, raise abilities, 'to deepen understanding of learned knowledge', 'to set a theme and find problem', 'to study and learn independently', 'to analysis information', 'to interest and concern with this field' and etc.

Finally, it is found that Group 3, 'Activities relating to software use' is useful for raising Category III 'Awareness relating to computer'. Activities to operate Word, Excel and PowerPoint using a personal computer raise computer operating skill, interest and concern with computers, understanding of computers, and expansion of computer utilization method and scene.

In this way, it is found that various abilities are raised by allowing a student to do many interactive activities in a class and outside a class.

\subsection{Classifying Students According to Principal Components in Rating Scale Values of Awareness}

Cluster analysis was conducted using the principal component scores in section 3.5 as a variable. The result showed that 26 students were classified into four student groups S1 to S4. 
In section 3.5, analysis of variance and multiple comparison for elongation of the consciousness of their groups found the following relations: $\mathrm{S} 2=\mathrm{S} 1>\mathrm{S} 3>\mathrm{S} 4$ for awareness cluster $\mathrm{G} 1 ; \mathrm{S} 2>\mathrm{S} 1=\mathrm{S} 3=\mathrm{S} 4$ for $\mathrm{G} 3 ; \mathrm{S} 2=\mathrm{S} 3>\mathrm{S} 1>\mathrm{S} 4$ for $\mathrm{G} 2$; and $\mathrm{S} 2>\mathrm{S} 3>\mathrm{S} 1=\mathrm{S} 4$ for $\mathrm{G} 4$. Student group $\mathrm{S} 2$ has a strong consciousness in the whole. S3 is higher than $\mathrm{S} 1$ in consciousness group G2 and G4, is not different from S1 in group G3, and is lower than S1 in G1. In addition, the elongation of the S4 group means small in total as only the elongation of the S4 group is smaller than that of other groups.

It was shown as the result of section 3.6 that consciousness group G3 and G4 in student group S2 developed well. Consciousness group G2 in student group S3 developed well and G4 followed. G1 in student group S1 developed well. Three student groups seem to be different in the consciousness that developed well.

It is necessary to devise a valuable method so as to raise the elongation of 11 students belonging to S4 than the present and to improve consciousness than that in other groups. It is suggested that it is necessary to think about changing an instruction method different from other groups.

\subsection{Extraction of Major Items in Each Group by Discriminant Function Analysis}

As for the average of the elongation in the consciousness of student group S2, all except one item of consciousness group G4 is higher than the average of total. The average of the elongation in the consciousness of group S3 is higher than the overall average for the 17 items of 1/8 items in group G1, 7/7 items in group G2, 2/6 items in group G3, and 8/9 items in G4. The average of the elongation in the consciousness of group S1 is higher than the overall average for the 14 items of $8 / 8$ items in group G1, 1/7 item of G2, 3/6 items in G3, and $2 / 9$ items in G4. The average of the elongation of the consciousness of group S4 was lower than the overall average. Group S4 has no major item and does not improve very much consciousness in comparison with other groups generally.

It is understood that average of the elongation in the consciousness of three groups S2, S3 and $\mathrm{S} 1$ is a little different according to the discriminant analysis. From these, the result of the analysis in section 3.5 was the same as the result of section 3.6.

\section{Conclusion}

In this study, we designed and practiced a course to make students create PowerPoint slides for book recommendation by applying the idea of active learning. Students selected books they recommended, researched them, considered the contents of the slides, created the slides, added animations and recorded narrations. Furthermore, they watched others' slides and learned from them. They mutually evaluated and commented. After all this, they revised, watched and evaluated the slides again. By interacting with other students for completing the task in this way, they were able to experience active evaluation and revision activities. In consequence, they enhanced problem-solving skills and nurtured active thinking through the classroom practice.

The findings from this class can be summarized as follows. 
(1) Total time taken for surveys of explanations and creation of slides, the creation of product presentation slides and the creation of reports was 15.8 hours on average.

(2) Total narration time for projects was 100.7 seconds on average.

(3) Assessment values for awareness relating to skills were felt to have improved overall.

(4) Statistical significance tests for each category for awareness relating to skills showed awareness in all 30 categories was felt to have improved overall.

(5) The result of cluster analysis for principal component scores showed that students were classified in four student groups S1 - S4. The result of cluster analysis for principal component scores showed that consciousness was classified in four consciousness groups G1 - G4.

(6) By analysis of variance and discriminant analysis, student group S1 is the group which 'awareness related to information gathering, management and analysis' is raised well. Student group S2 is the group which 29 items except the item (2) are higher than the average of the total and consciousness improved most generally. Student group S3 is the group which "consciousness related to a feeling of satisfaction and accomplishment" and "consciousness related to the understanding for the computer, creativity, and ability to evaluate oneself" are enhanced well. Student group S4 does not improve very much generally and has the approximately lowest elongation for all consciousness.

(7) The characteristics of four student groups shown by cluster analysis conducted using the principal component scores were as follows: the group that 'the awareness related to information gathering, management and analysis' has been well raised, the group that 'awareness of learning and deep understanding by using computers' and 'awareness of understanding, creative and evaluation skills towards computers' have been well raised, the group that 'awareness of self-satisfaction and self-achievement' has well raised, and the group that almost of elongation in awareness is lowest.

In the future, we would like to compare useful activities in improving attitude in class with them in creating slides to introduce product (Miyaji 2015a, 2015b) by analyzing the post survey of attitude. In addition, we would like to compare the effects of the above-mentioned storytelling (Miyaji 2012a, 2012b) and the effects of this class. We would also like to apply innovation to class methods to improve learning ability for students with a wide range of learning abilities.

\section{Acknowledgement}

The author appreciates the support of the Grant-in-Aid for Scientific Research, foundation study (C25350364) provided by the Ministry of Education, Culture, Sports, Science and Technology, Japan for this research. The author would like to express appreciation to the students who were surveyed and who helped collect educational information.

\section{References}

Barrett, H.C. (2006). Researching and Evaluating Digital Storytelling as a Deep Learning 
Tool, SITE2006 Proceedings of Society for Information Technology \& Teacher Education International Conference, pp.647-652, Orlando, USA.

Cappuccio, G. (2015). Digital Storytelling at the University, INTED2015 Proceedings of the 9th International Technology, Education and Development Conference, pp.5204-5210, Madrid, Spain.

Figg, C., McCartney, \& R., Gonsoulin, W. (2010). Impacting Academic Achievement with Student Learners Teaching Digital Storytelling to Others: The ATTTCSE Digital Video Project. Contemporary Issues in Technology and Teacher Education (CITE Journal), 10(1), 38-79.

Kelleher, C., \& Pausch, R. (2007). Using Storytelling to Motivating Programming, Communications of the ACM, 50(7), 59 - 64. https://doi.org/10.1145/1272516.1272540

Ministry of Education, Culture, Sports, Science and Technology Council. (2012). Continue Learn towards the Qualitative Transformation of University Education in Order to Build a New Future - to the University to Continue Learning throughout the Life and Foster the Ability to Think Proactively (Report), http://www.mext.go.jp/b_menu/shingi/ chukyo/chukyo0/toushin/1325047.htm.

Miyaji, I. (Ed.) (2009). Toward Blended Learning from E-learning, Tokyo: Kyoritu-Shuppan.

Miyaji, I. (2010). The Effects of Digital Storytelling through the Strategy of Phased Evaluation and Correction, ITHET2010 Proceedings of the 9th International Conference on Information Technology Based Higher Education and Training, pp.138-143, Cappadocia, Turkey.

Miyaji, I. (2012a). Evolution of Literacy in Software Functions by Creation of Storytelling, ICCE 2012 Proceedings of the 20th International Conference on Computers in Education, KONG, S.C., et al. (Eds.), pp.682-689, Singapore.

Miyaji, I. (2012b). Effects of Creating Three Kinds of Digital Storytelling on Student Attitude, Journal of Modern Education Review, 2(5), 243-262.

Miyaji, I. (2015a). Change of Attitude in Class for Creating Slides to Present Product, eLEOT2015 Proceedings of the 2nd International Conference on e-Learning, e-Education, Online Training, pp.25-30, Novedrate, Italy.

Miyaji, I. (2015b). Useful Activities in Improving Attitude in Class for Creating Slides to Present Product, LICE 2015 Proceedings of the London International Conference on Education, pp.293-298, London, UK.

Miyaji, I. (2016a). Improvement in Computer Literacy through Creating Digital Storytelling, American Journal of Education Research, 4(1), 54-63. https://doi.org/10.1109/2.901164

Miyaji, I. (2016b). Useful Activities for Improving Attitude in Creating Book Recommendation Slides by Means of PowerPoint, LICE 2016 Proceedings of the London International Conference on Education, pp.35-40, London, UK.

Richardson, J. (2016). The Potential of Narrative Pedagogies: Utilizing Educational Technologies for Digital Storytelling in Engineering Programmes, ICERI2016 Proceedings of the 9th annual International Conference of Education, Research and Innovation, pp.17, Seville, Spain. https://doi.org/10.21125/iceri.2016.1004 
Robin, B. R. (2008). Digital Storytelling: A Powerful Technology Tool for the 21st Century Classroom. Theory into Practice, 4(3), 220-228. https://doi.org/10.1080/00405840802153916

Tsou, W., Wang, W., Tzeng, Y. (2006). Applying a Multimedia Storytelling Website in Foreign Language Learning. Computers \& Education, 47(1), 17-28. N.C.S. https://doi.org/10.1016/j.compedu.2004.08.013

Wilujeng, N.C.S., Ekowati, V.I., Sudarmaji, S. (2017). Storytelling in High Education Institutions: How to Enrich the Learning Experience in Multidiscipline Areas?. END2017 Proceedings of the 11th International Technology, Education and Development Conference, pp.9170-9180, Valencia, Spain. https://doi.org/10.21125/inted.2017.2167

Zipes, J. (1995). Creative Storytelling: Building Community, Changing Lives, New York \& London: Routledge. 